\title{
Condiciones laborales de migrantes bolivianas que realizan trabajo de cuidado en Iquique
}

\section{Labor conditions of Bolivian migrants who provide care work in Iquique}

\author{
Sandra Leiva Gómez ${ }^{* *}$ \\ Instituto de Estudios Internacionales, Universidad Arturo Prat \\ Miguel Ángel Mansilla Agüero*** \\ Instituto de Estudios Internacionales, Universidad Arturo Prat \\ Andrea Comelin Fornes ${ }^{* * * *}$ \\ Facultad de Ciencias Jurídicas y Políticas, Universidad Arturo Prat
}

Recibido: 18.01.2017 Aprobado: 17.04.2017

\begin{abstract}
Resumen
Cada vez es más frecuente en Chile la contratación de servicio doméstico extranjero para realizar el trabajo de cuidado de personas dependientes. Las trabajadoras domésticas migrantes por lo general han dejado a sus hijos en su país de origen a cargo de otra persona, conformándose cadenas globales de cuidado. Mediante entrevistas efectuadas en la ciudad de Iquique a trabajadoras domésticas bolivianas, quienes realizan labores
\end{abstract}

Este artículo forma parte de un proyecto más amplio financiado por CONICYT, ANILLO SOC 1109 "Relaciones transfronterizas entre Bolivia y Chile: Paradiplomacia y prácticas sociales 1904-2004”, llevado a cabo por investigadores del Instituto de Estudios Internacionales de la Universidad Arturo Prat y del Instituto de Estudios Avanzados de la Universidad de Santiago de Chile. El artículo responde asimismo a los avances de investigación de un proyecto interno de la Universidad Arturo Prat. Los autores agradecen al fondo interno de la VRIIPUNAP el financiamiento para el desarrollo del proyecto interno código VRIIP 0035-16. También manifiestan su agradecimiento especialmente a la Hermana Ema Hormazábal, de la Congregación del Buen Pastor, y a Janett Gómez, de la Pastoral Migratoria de Iquique, así como a las cuidadoras bolivianas entrevistadas.

** Doctora en Sociología, Universidad de Göttingen; investigadora del Instituto de Estudios Internacionales, Universidad Arturo Prat. Correo electrónico: sandleiva@gmail.com.

*** Doctor en Antropología, Universidad de Tarapacá; investigador del Instituto de Estudios Internacionales, Universidad Arturo Prat. Correo electrónico: mansilla.miguel@gmail.com.com.ar

**** Magíster en Educación Superior, investigadora de la Facultad de Ciencias Jurídicas y Políticas, Universidad Arturo Prat. Correo electrónico: ancomelin@gmail.com. 
de cuidado sin contar con un permiso laboral, se analizan sus condiciones laborales. Tal situación origina condiciones precarias de empleo, extensas jornadas de trabajo y malos tratos. Se concluye en primer lugar que para otorgar la adecuada protección legal a las trabajadoras domésticas bolivianas en Iquique, la legislación nacional debiera contemplar los casos de trabajadores en zonas fronterizas. En segundo lugar, la modificación a la ley de trabajadoras domésticas podría ser beneficiosa para las cuidadoras de zona fronteriza, en tanto posibilitaría el canje de días libres, favoreciendo el que ellas puedan realizar visitas frecuentes a sus hijos dejados en Bolivia. En tercer lugar, podría pensarse en políticas migratorias innovadoras, como por ejemplo, liberar a ciertos migrantes de obtener un permiso de trabajo, cuando se trate de empleos que el país necesite cubrir de manera urgente y respecto de los cuales la población migrante sea una solución.

Palabras claves: trabajo, cuidado, migración.

\begin{abstract}
It is increasingly common for Chileans to hire foreign domestic workers to care for dependent individuals in their households. Migrant domestic workers generally leave their children in the care of another person in their country of origin, thus creating global care chains. Labor conditions are analyzed through interviews conducted in the city of Iquique with Bolivian domestic workers who provide care services without a work permit. This situation can lead to precarious work conditions, long workdays and mistreatment. The authors conclude that national legislation must address the cases of workers in border areas in order to provide adequate legal protection for Bolivian domestic workers in Iquique. Second, they find that changes to the domestic workers law could be beneficial for caregivers in the border area as this would provide for the exchange of days off, allowing them to make frequent visits to the children left behind in Bolivia. Third, innovative migratory policies could be designed, such as freeing certain migrants from the work permit requirement when they are performing work that the country urgently needs and for which the migrant population provides a solution.
\end{abstract}

Keywords: work, care, migration. 


\section{Introducción}

La labor de cuidado realizada por las trabajadoras domésticas juega un papel fundamental. Así, normalmente ellas se hacen cargo del cuidado de niños o ancianos mientras la empleadora está participando en el mercado laboral. En Chile han comenzado a contratarse en forma creciente personas extranjeras para desarrollar esta labor (Stefoni, 2009), quienes por lo general han delegado el trabajo de cuidado de sus propios infantes y adultos dependientes a otra persona, conformando cadenas globales de cuidado. Existen publicaciones sobre cadenas globales de cuidado entre Perú y Chile (Arriagada y Todaro, 2012; Arriagada y Moreno, 2011; Acosta, 2015, 2013), pero solamente se conoce un estudio sobre estas cadenas entre Bolivia y Chile (Comelin y Leiva, 2017). El presente texto pretende aportar a este conocimiento, entregando antecedentes sobre las condiciones laborales de las trabajadoras domésticas bolivianas que realizan un trabajo de cuidado remunerado y que forman parte de una cadena global de cuidado.

La escasez de una adecuada oferta estatal y privada para el cuidado de dependientes, el aumento de la participación laboral femenina, el envejecimiento de la población, sumados a las desigualdades económicas entre los países llamados de origen y destino, entre otras razones, determinan que entre estos se conformen cadenas globales de cuidado (Yeates, 2012; Salazar Parreñas, 2001). Sin embargo, ello trae aparejadas nuevas problemáticas para las migrantes, tanto en sus familias dejadas en el país de origen como en sus condiciones de vida en el país de destino, entre ellas la reestructuración familiar en ambas naciones y la triple discriminación (Parella, 2003) que en variadas ocasiones sufren, constituyendo la clase social, el género y la etnia importantes factores de segregación. En este contexto, las condiciones laborales en que las migrantes ejercen tareas de cuidado son una importante preocupación. Se conocen algunos estudios que entregan antecedentes sobre las condiciones laborales de las migrantes en Chile, principalmente de peruanas que han dejado a sus hijos en su país de origen y que realizan trabajo de cuidado (Acosta, 2015; Arriagada y Moreno, 2011; Arriagada y Todaro, 2012), los que dan cuenta de situaciones laborales desmejoradas. Las mujeres entrevistadas para esas investigaciones vivían en Santiago y la mayoría de ellas contaba con un contrato de trabajo. La novedad del estudio que da cuenta este artículo, es que se trata de cuidadoras bolivianas que no tienen contrato de trabajo y que viven en Iquique, ciudad cercana a la frontera con Bolivia. Esta condición fronteriza determina una realidad distinta a las migrantes que no viven cerca de su país de origen.

Esta investigación pretende, por consiguiente, aportar un plus a las ya existentes -además de situar a Bolivia y Chile como eslabones de la cadena-, en tanto estudia 
la realidad laboral de migrantes bolivianas que realizan cuidado remunerado en una zona fronteriza: la Región de Tarapacá. En zonas fronterizas se da un tipo especial de migraciones, llamada por algunos migración de "idas y venidas" (Hinojosa, Pérez y Cortez, 2000). La migración fronteriza no necesariamente persigue el establecimiento en un territorio o lugar, sino que más bien muchas veces lo que hace es generar una circulación de personas (Tarrius, 2000). Así, el término de circulación migratoria es acuñado para referirse a migrantes que se desplazan a otro lugar de manera temporal, repetitiva o cíclica, sin la intención de una residencia permanente o de largo plazo (Cortés, 2009). Considerando este tipo especial de migración en Iquique, se busca analizar aquí cuáles son las implicancias de realizar labores de cuidado en una zona fronteriza, sobre las condiciones laborales de las migrantes.

El objetivo de este artículo, por tanto, es describir y analizar las condiciones laborales de trabajadoras domésticas bolivianas fronterizas que realizan trabajo de cuidado remunerado - que forman parte de una cadena global de cuidado entre Chile y Boliviaen la ciudad de Iquique. En lo que concierne al trabajo de cuidado propiamente tal, este puede ser realizado con o sin remuneración: cuando no se remunera se trata normalmente del cuidado de los propios hijos o sus padres adultos mayores (Gonzálvez y Acosta, 2015), mientras que el cuidado remunerado recae en algunas instituciones o es realizado por trabajadoras domésticas. En este artículo se analizan las condiciones laborales del cuidado remunerado que proporcionan las trabajadoras domésticas bolivianas.

La estructura del texto responde a la siguiente progresión: a continuación se revisan algunos aspectos conceptuales sobre el trabajo de cuidado y las cadenas globales de cuidado. Posteriormente, se entregan algunos antecedentes sobre el aumento de la migración boliviana en Chile y la oferta de trabajo de cuidado que las migrantes bolivianas realizan. Después se expone sobre la metodología utilizada en el estudio y luego se realiza una caracterización de las cuidadoras bolivianas con relación al trabajo de cuidado que prestan en Iquique, entregando antecedentes para visualizar su posición en la conformación de una cadena global de cuidado. Enseguida, se analizan las condiciones laborales de las migrantes indicadas, destacando la ausencia de un contrato escrito, remuneración, modalidad de empleo, jornada laboral, protección social y trato brindado por los empleadores. El texto finaliza con las conclusiones de los resultados y con propuestas para solucionar los problemas analizados. 


\section{Trabajo de cuidado y cadenas globales de cuidado}

El cuidado de las personas dependientes es llevado a cabo generalmente por las mujeres. Sin embargo, han ocurrido una serie de transformaciones que han devenido en una carencia del rol de cuidadora. Así, los cambios en las preferencias de las mujeres al darles más prioridad a sus proyectos personales, el incremento de la participación laboral femenina, el envejecimiento poblacional y las transformaciones en la familia, entre otros varios determinantes, han provocado una carencia de personas que realicen esta labor de cuidados. Al existir en Chile una limitada provisión por parte del Estado de servicios de cuidado (Leiva, 2015), muchas mujeres optan por la contratación de servicio doméstico. Como en el país no existe una suficiente oferta de trabajadoras domésticas nacionales, en los últimos diez años se ha debido contratar servicio doméstico extranjero (Stefoni, 2009).

En ciertas épocas de nuestra vida, como la niñez y la vejez, las personas presentamos dependencia y necesitamos que otros nos proporcionen servicios de cuidado (Fernández y Tobío, 2007). Esta labor implica un componente material (pues lleva asociado un trabajo físico), uno afectivo o emocional, y un componente de organización y costos económicos (Batthyáni, 2004; Pérez Orozco y López Gil, 2011). El cuidado involucra variados aspectos, entre ellos las relaciones entre la persona que cuida y la que recibe los cuidados, así como el marco institucional en que se prestan los servicios de cuidado (Thomas, 1993). El enfoque del social care (traducido al castellano como organización social del cuidado) considera la prestación de cuidados a personas dependientes entregada por diversas instituciones sociales (Lewis, 1998) analizando el papel del Estado, el mercado, las familias y la comunidad. Para nuestro análisis nos focalizaremos en la contribución que realiza el mercado a través de las trabajadoras domésticas.

La literatura internacional da cuenta de numerosas investigaciones sobre la contratación de migrantes para realizar el trabajo de cuidado de niños y ancianos (Parella, 2003; Williams, 2012), el que ha sido documentado en estudios sobre familias transnacionales (Rivas y Gonzálvez, 2009; Ariza, 2012), maternidad transnacional (Hondagneu-Sotelo y Avila, 1997), circulación de cuidados (Baldassar y Merla, 2014) y cadenas globales de cuidado (Hochschild, 2001; Salazar Parreñas, 2001). Cuando una mujer emigra a un país para cuidar a los hijos de otra mujer, dejando a los suyos en su país de origen a cargo de otra persona, se habla de una cadena global de cuidado (Pérez Orozco, 2007). La literatura internacional alude a este fenómeno con el concepto de "fuga de cuidados", en tanto las cuidadoras emigran de su sociedad de origen a otro país (Bettio, Simonazzi y Villa, 2006), produciéndose paralelamente una circulación de cuidados (Baldassar y 
Merla, 2014) en esa sociedad de origen, al asumir otros miembros del hogar la función de prestación de cuidados.

Con todo, dar cuenta del debate teórico sobre estos diversos enfoques excede las pretensiones de este artículo. Aquí se mencionan solamente algunas nociones que vinculan el trabajo de cuidado con las migraciones, considerando el enfoque transnacional en el análisis, el que remite a la idea de un "desborde" del Estado nación, en un sentido tanto político, social, organizacional y geográfico. Se pretende así superar el nacionalismo metodológico que se tornaba insuficiente para comprender adecuadamente la migración (Cortés, 2009). Sin embargo, los enfoques transnacionales también presentan sus puntos ciegos, ya que no siempre ofrecen suficientes categorías explicativas de la realidad, y en ocasiones no han integrado adecuadamente el contexto al análisis (Grimson y Guizardi, 2015). Así, la condición fronteriza de las trabajadoras domésticas que realizan trabajo de cuidado permite visualizar elementos en el despliegue del cuidado remunerado que antes no habían sido lo suficientemente analizados.

\section{Oferta de trabajo de cuidado de migrantes bolivianas en Chile}

Bolivia posee una elevada pobreza y una importante desigualdad socioeconómica (Wanderley, 2009), constituyéndose en razones que llevan a su población a migrar. Se han realizado estudios que analizan las cadenas globales de cuidado entre Bolivia y España (Salazar, Jiménez y Wanderley, 2010), así como las familias transnacionales entre ambos países (Hinojosa, 2009). Si antes era España uno de los destinos favoritos de la migración boliviana, debido a la crisis económica que experimentó este país europeo en los últimos años, esta se redirigió a Brasil y Chile (Baby-Collin y Cortés, 2014).

La migración ha aumentado considerablemente en Chile en el último quinquenio. Si en el año 2009 los 352.344 migrantes constituían el 2,08\% de la población (Departamento de Extranjería y Migración, 2010), en 2014 los 410.988 migrantes representaban el 2,3\% de la población nacional. En este contexto nacional, el colectivo boliviano adquiere cada vez más peso dentro de estas cifras: en 2009 , los 24.116 bolivianos residentes representaban el 6,8\%, en tanto que en el año 2014, los 36.036 bolivianos residentes constituían el 8,8\% de la población extranjera en Chile (Departamento de Extranjería y Migración, 2016). 
Muchas familias chilenas utilizan el servicio doméstico como una estrategia que les permite conciliar la vida familiar y laboral (Leiva y Comelin, 2015), sobre todo teniendo en cuenta el sostenido aumento de la participación laboral femenina en el país en los últimos diez años, que de un 32,5\% registrada en 1990 subió a un 45,6\% en 2013 (Ministerio de Desarrollo Social, 2015). En un contexto de insuficiente mano de obra nacional que permita cubrir el trabajo doméstico, se ha optado por contratar servicio doméstico extranjero, principalmente peruano (Stefoni, 2009). Sin embargo, hay evidencia de que en los últimos años las familias están contratando también servicio doméstico boliviano (Correa y Vidal, 2013). Las cifras muestran que entre los años 2004 y 2011 había 526 migrantes bolivianas inscritas para realizar trabajo doméstico en el Centro Integrado de Atención a Migrantes (CIAMI), ubicado en Santiago (Martínez y Soffia, 2013), mientras que en Iquique en el primer semestre del año 2010, las 374 migrantes bolivianas atendidas expresaban su voluntad por trabajar en el servicio doméstico (Ramos y Urbina, 2012).

\section{Metodología}

El estudio del que da cuenta este artículo tuvo un carácter exploratorio y en él se utilizó una metodología cualitativa, realizando entrevistas en profundidad a migrantes bolivianas e informantes claves y, a la vez, se revisó literatura especializada en la materia. Diez mujeres bolivianas que trabajan en el servicio doméstico y que además prestan labores de cuidado en la ciudad de Iquique, fueron las entrevistadas. Ellas forman parte de una cadena global de cuidado, en tanto sus hijos viven en Bolivia a cargo de otra persona. Se entrevistó, además, a seis informantes claves pertenecientes a la Pastoral Migratoria y a la Congregación del Buen Pastor, a fin de registrar su conocimiento experto sobre el trabajo doméstico realizado por las migrantes bolivianas. El número de entrevistas fue establecido de acuerdo con la saturación de información y se efectuaron entre septiembre y octubre de 2015.

Las trabajadoras domésticas entrevistadas se seleccionaron de acuerdo con una muestra teórica (Glaser y Strauss, 1967), según determinadas características para responder al objetivo estudiado: son mujeres que han llegado hace poco tiempo a Iquique o que están saliendo y entrando con cierta frecuencia al país; que realizan trabajo de cuidado dentro de su trabajo doméstico; que han dejado a sus hijos en Bolivia a cargo de otra persona y que trabajan en la ciudad de Iquique. Se escogió esta muestra teórica para describir y analizar las condiciones laborales de las migrantes bolivianas que trabajan como cuidadoras en una zona fronteriza. 
A la totalidad de los entrevistados se les aplicó un consentimiento informado, el que fue debidamente revisado por los comités de ética de las universidades que patrocinaron el proyecto. Las entrevistas fueron grabadas con el permiso de los entrevistados, siendo posteriormente transcritas y analizadas con el software de análisis cualitativo N-VIVO. Para ello se establecieron categorías previas de análisis, considerando además las categorías emergentes que fueron manifestándose durante el estudio.

\section{El trabajo de las cuidadoras bolivianas en Iquique}

En este apartado se realiza una breve caracterización de las cuidadoras bolivianas entrevistadas con relación al trabajo de cuidado desempeñado y su rol en la conformación de una cadena global de cuidado. Se explica además el contexto jurídico específico de las migrantes bolivianas y cómo este configura cierta modalidad de migración. Se entregan aquí algunos antecedentes sobre los trámites que ellas deben realizar para trabajar legalmente en el país ${ }^{1}$, relativos a cómo consiguen trabajo en Iquique y el papel que desempeñan algunas instituciones eclesiásticas en la ciudad, que prestan ayuda a las migrantes.

\section{Caracterización de las cadenas globales de cuidado}

Las diez cuidadoras migrantes entrevistadas tienen a todos sus hijos viviendo en Bolivia, cuyo número fluctúa entre uno y cinco hijos (ver Cuadro $\mathrm{N}^{\circ} 1$ ). Algunas de ellas son madres de hijos pequeños, otras de adolescentes y otras de personas ya adultas. Los hijos pequeños o adolescentes de las migrantes bolivianas han quedado a cargo del marido o de familiares, lo que refleja realidades familiares monoparentales, situación que se ha ido acrecentando en América Latina (Salvo y Gonzálvez, 2015). Tres de las migrantes han dejado a sus hijos bajo la custodia de sus maridos, incluso una de ellas ha dejado a sus hijos a cargo del exmarido. Otra le encargó sus hijos a su hermana, otra los dejó a cargo de su madre, y dos de ellas, bajo la responsabilidad de su padre. Solamente cuando los hijos son adultos y han formado su propia familia, no han quedado a cargo de sus parientes, que es la situación de dos entrevistadas.

$1 \quad$ Estos valores corresponden al segundo semestre de 2015, momento en que se realizó el trabajo de campo. 
Todas las mujeres bolivianas entrevistadas realizan labores de cuidado. Ocho de ellas cuidan a niños o a adolescentes, en tanto dos de ellas asisten a ancianos, para lo cual trabajan en casas particulares, ya sea puertas adentro o afuera. Provienen de diversas ciudades: La Paz, El Alto, Cochabamba, Potosí y Santa Cruz. Todas establecen contacto frecuente con sus hijos, incluso algunas todos los días a través de WhatsApp; otras una o más veces a la semana vía contacto telefónico en cabinas públicas, en tanto que otras utilizan tecnologías como Facebook o Skype ${ }^{2}$. A continuación, el Cuadro $\mathrm{N}^{\circ} 1$ muestra una caracterización de las cuidadoras bolivianas entrevistadas, en tanto forman parte de una cadena global de cuidado ${ }^{3}$.

\section{Cuadro No 1: Caracterización de las cuidadoras bolivianas en la cadena global de cuidado}

\begin{tabular}{|l|c|l|l|l|l|}
\hline Nombre & $\begin{array}{c}\text { Cantidad } \\
\text { de hijos } \\
\text { en } \\
\text { Bolivia }\end{array}$ & $\begin{array}{l}\text { Edades de sus } \\
\text { hijos }\end{array}$ & $\begin{array}{l}\text { A cargo de quién } \\
\text { han quedado los } \\
\text { hijos (en relación } \\
\text { con la cuidadora) }\end{array}$ & $\begin{array}{l}\text { Edades de } \\
\text { niños o } \\
\text { ancianos } \\
\text { cuidados }\end{array}$ & $\begin{array}{l}\text { Ciudad de } \\
\text { procedencia }\end{array}$ \\
\hline Lorena & 2 & 16,15 & Marido & $3,3,3$ & El Alto \\
\hline Cecilia & 5 & $28,24,22,20$, & Solos, grandes & 86 & Cochabamba \\
\hline Miriam & 2 & 45,39 & Solos, grandes & 90 & La Paz \\
\hline Norma & 2 & 15,12 & Padre & 8 & El Alto \\
\hline Lilian & 1 & 4 & Marido & 17,10 & Potosí \\
\hline Soledad & 1 & 13 & Padre & 13,10 & La Paz \\
\hline Delia & 4 & $13,11,6,3$ & Madre & $10,7,5$ & Santa Cruz \\
\hline Nélida & 3 & $12,10,3$ & Marido & 15,12 & Cochabamba \\
\hline Cintia & 4 & $24,20,15,6$ & Hermana & $6,4,2$ & La Paz \\
\hline Sara & 2 & 19,14 & Exmarido & 23,18 & La Paz \\
\hline
\end{tabular}

Fuente: elaboración propia, sobre la base de entrevistas realizadas (Leiva y Ross, 2016).

2 La Congregación del Buen Pastor ayuda a que las familias mantengan el contacto, para lo cual ofrece capacitaciones a migrantes bolivianas, proporcionándoles acceso gratuito al uso de computadores. La Congregación tiene un proyecto Chile-Bolivia en conjunto con la Fundación Levántate Mujer.

3 Los nombres han sido cambiados para resguardar su anonimato. Las entrevistas fueron realizadas siguiendo procedimientos éticos garantizados a través de un consentimiento informado. 


\section{Trabajo en una zona fronteriza de Chile y Bolivia}

El total de las entrevistadas se encuentra en una condición regular. Han entrado con visa de turista, lo que implica que, para permanecer en el país, cada noventa días deben salir y volver a ingresar al territorio nacional. El contacto frecuente que tienen con las organizaciones de la Iglesia (ya sea como casa de acogida, para recibir almuerzo a muy bajo costo, para buscar trabajo, o para recibir asesoría jurídica) hace que estén conscientes de que deben permanecer en una condición regular, puesto que el vencimiento de sus permisos, en este caso de la visa de turismo, implica sanciones migratorias de altos costos que ellas no están en condiciones de solventar. El Departamento de Extranjería y Migración establece que de vencerse el permiso para permanecer en el país, trátese del permiso de residencia o de turismo, y ya han pasado entre uno y cien días en esta situación, el migrante debe cancelar una multa de \$34.201 si se presenta voluntariamente, y de $\$ 45.083$ si se trata de una denuncia a la Policía de Investigaciones, valores que rigen para el segundo semestre de $2015^{4}$.

Para poder trabajar de manera legal, las migrantes bolivianas deben solicitar una visa temporaria con convenio MERCOSUR 5 con permiso de trabajo, para lo cual deben presentar su pasaporte. Una vez que realizan este trámite, no tienen necesidad de estar saliendo cada noventa días del país - como es el caso de la visa de turista-. Algunas no realizan este trámite porque lo desconocen, pero otras no lo efectúan porque les resulta bastante oneroso, ya que cuesta US $\$ 283^{6}$ para ciudadanos bolivianos, cifra que equivale aproximadamente a $\$ 197.000$. El permiso de trabajo tiene un valor de US\$150 para las personas de Bolivia, aproximadamente $\$ 104.000$, y disponen de treinta días para pagarlo. Contrasta el caso de los migrantes peruanos, pues no rige el convenio MERCOSUR entre Chile y Perú, por lo que para solicitar la visa temporaria por motivos laborales deben presentar un contrato de trabajo escrito. Cabe destacar que si los ciudadanos bolivianos quisiesen optar más adelante a la residencia definitiva, requieren haber trabajado con un contrato de trabajo durante un año y haber realizado las imposiciones correspondientes ${ }^{7}$.

Información consultada el 5 de noviembre de 2015, disponible en http://www.extranjeria.gob.cl/faq/\#sanciones. Existe una legislación especial para los ciudadanos bolivianos, establecida en el Acuerdo sobre Residencia para Nacionales de los Estados Parte del MERCOSUR, Bolivia y Chile. A partir de 2009 se implementó este acuerdo en Chile, el que dispone que los ciudadanos de los miembros de MERCOSUR, Bolivia, Argentina, Brasil, Uruguay y Paraguay pueden obtener una visa temporaria por un año, sin necesidad de contar con un contrato de trabajo, prorrogable por igual período (Tapia, 2015).

6 Los valores de las visas temporarias y permisos de trabajo varían dependiendo de la nacionalidad del migrante.

7 El Departamento de Extranjería y Migración realizó en marzo de 2015 una modificación a la visa para trabajar. Antes existía únicamente la visa sujeta a contrato, según la cual un migrante debía trabajar dos años con el mismo empleador, y solo después de ello podía optar a la residencia definitiva. En marzo de 2015 se creó la visa 
Resulta interesante reparar en este constante trajín fronterizo, según relata una informante clave, quien afirma que "las bolivianas van, vienen, van, vienen, van, vienen" (Informante Clave 1, perteneciente a la Congregación del Buen Pastor). En una zona fronteriza, como es Iquique respecto de Bolivia, es común el movimiento poblacional, que refleja una circulación de personas (Tapia y González, 2014; Tapia y Parella, 2015) o una migración circular (Leiva y Ross, 2016; Comelin y Leiva, 2017). Esta circularidad se ve acrecentada en este caso por los acuerdos entre Chile y Bolivia, entre ellos, el acuerdo de poder ingresar al país libremente sin mayor trámite, otorgándosele un permiso de turismo al ingreso, y el acuerdo de los estados del MERCOSUR, que los habilita para permanecer un año en el país sin contar con un contrato de trabajo.

\section{Organizaciones eclesiales y asesoría laboral como soporte a las cadenas globales de cuidado}

Muchas cuidadoras bolivianas consiguen el trabajo en Iquique a través de la Pastoral Migratoria, perteneciente a INCAMI (Instituto Católico Chileno de Migración) ${ }^{8}$. Cuando las migrantes recién llegan a la ciudad, varias de ellas acuden a la Pastoral Migratoria, la que cuenta con una casa de acogida ${ }^{9}$. La casa de acogida en Iquique tiene capacidad para dieciséis mujeres migrantes, pero también puede recibir a más si es necesario. En la Pastoral Migratoria se les da asesoría social y jurídica, se presta también un servicio de acompañamiento, se les proporciona almuerzo y se les ofrece una bolsa de trabajo. Los servicios son totalmente gratuitos, salvo la comida, por la cual se les solicita una muy baja cantidad de dinero. Otra organización que entrega asesoría jurídica y laboral a las migrantes, en su mayoría a migrantes bolivianas, es la Congregación del Buen Pastor. Esta institución, en conjunto con la Fundación Levántate Mujer, ubicada en Bolivia, llevó a cabo un proyecto que tuvo por finalidad ayudar a que las mujeres bolivianas en Chile mantuviesen el contacto con sus familias en su país de origen. El proyecto se tituló “Telecentro: Oruro-Antofagasta-Iquique. Construyendo redes entre Bolivia y Chile” y fue financiado por Irlanda. A pesar de que el proyecto ya concluyó, hoy la congregación sigue prestando ayuda a migrantes, y además de proporcionar asesoría jurídica y laboral,

temporaria por motivos laborales, según la cual el migrante debe trabajar con un contrato de trabajo y estar imponiendo durante un año, sin necesidad de trabajar para el mismo empleador.

8 INCAMI es un organismo de la Conferencia Episcopal, fundado en Chile en 1955, cuyo eje central es la integración e inclusión de los migrantes. Cuenta con trece delegaciones a lo largo de todo el país (www.incami.cl).

9 INCAMI ha establecido siete casas de acogida a las migrantes, ubicadas en Arica, Iquique, Antofagasta, Copiapó, Valparaíso, Santiago y Concepción. 
realiza talleres de gastronomía, computación, desarrollo personal, y entrega también acompañamiento y contención cuando es necesario.

\section{Condiciones laborales de las cuidadoras bolivianas en Iquique}

Se conocen algunos estudios que analizan las condiciones laborales de las cuidadoras migrantes en Chile, aunque ellos se refieren en su mayoría a las trabajadoras domésticas peruanas (Arriagada y Moreno, 2011; Acosta, 2015; Stefoni, 2009), colectivo que desde mediados de la década de 1990 comenzó a aumentar en el país (Martínez, 2003). Las migrantes peruanas empleadas en el servicio doméstico suelen tener condiciones laborales precarias, realizando extensas jornadas laborales y a veces sujetas a malos tratos. Aunque la migración boliviana ha aumentado en el último quinquenio en el país, existe solo un par de estudios que se refieren a las condiciones laborales de las trabajadoras domésticas bolivianas en Chile, como el de Leiva y Ross (2016), que analiza la fragmentación de las trayectorias laborales de cuidadoras bolivianas, y el de Comelin y Leiva (2017), que se refiere a la migración circular de cuidadoras bolivianas. En esta sección se analizan las condiciones laborales de las cuidadoras bolivianas entrevistadas, entregando antecedentes sobre la inexistencia de contrato en su situación laboral, la modalidad de trabajo por la que se les contrata (puertas afuera o adentro), la jornada laboral, sus remuneraciones, su situación de previsión social y de salud, y por último, el trato recibido.

\section{Ausencia de contrato de trabajo}

Ninguna de las mujeres entrevistadas está en posesión de un contrato de trabajo escrito, lo que las expone a ilegalidades y abusos laborales. Debe destacarse que no necesariamente las cuidadoras bolivianas quieren tener un contrato de trabajo. Algunas argumentan que les pagarían menos dinero, porque de ese sueldo se les rebajarían las imposiciones. Otras, sin embargo, se refieren a que si optasen a un contrato de trabajo, deberían permanecer un año en el país y no tendrían la posibilidad de viajar cada tres meses a ver sus hijos. En efecto, la visa temporaria por motivos laborales establece que los extranjeros deben trabajar un año con contrato de trabajo para luego optar a la residencia definitiva. Este es el caso de Norma (cuidadora boliviana de un niño), quien va cada dos meses y medio a visitar a sus dos hijos, de 12 y 15 años, que viven en El Alto, La Paz. Si bien a ella le 
ofrecieron firmar un contrato de trabajo y manifiesta que va a sacar sus documentos, está dudosa, pues le darían una visa temporaria, lo que implicaría estar un año sin viajar a Bolivia y no podría entonces visitar frecuentemente a sus hijos.

A Delia, otra migrante boliviana, la empleadora le ofreció firmar un contrato de trabajo: "La señora me va a sacar los papeles", cuenta (Delia, cuidadora boliviana de tres niños). Ella manifiesta estar de acuerdo, probablemente en razón de que a diferencia con otros casos de mujeres bolivianas, Delia tiene a sus hijos en Santa Cruz, y un viaje cada tres meses puede que no le resulte tan conveniente realizar debido a la mayor distancia que debe remontar, lo que le implica un mayor tiempo de viaje y desembolsar recursos monetarios que no está dispuesta a emplear en el traslado. Por el contrario, las migrantes que viven en La Paz, Oruro o Potosí, los tres departamentos colindantes con Chile, parecerían rechazar un contrato de trabajo, para así tener la posibilidad de viajar cada tres meses a visitar a sus hijos.

La ausencia de un contrato de trabajo se ve facilitada por la gran demanda de servicio doméstico migrante. Es relativamente fácil conseguir a trabajadoras domésticas bolivianas. La población local iquiqueña sabe que puede recurrir a la bolsa de trabajo de la Pastoral Migratoria, y aun cuando en esta organización se le solicita a la empleadora que le realice un contrato de trabajo a la empleada doméstica, esto no siempre sucede. A veces las empleadoras no solo no siguen el procedimiento, sino que rehúsan ingresar a las dependencias de la pastoral para evitar así registrarse. Es así como negocian directamente con las mujeres bolivianas y hacen trato con ellas afuera de la Pastoral. Ello hace todavía más difícil la firma de un contrato de trabajo y el cumplimiento de las condiciones laborales pactadas. Por otra parte, es probable que algunas empleadoras no quieran hacerles contrato de trabajo, en razón de que así pueden hacerlas trabajar más de lo que la legislación permite.

\section{Modalidad de trabajo: puertas afuera versus puertas adentro}

Las cuidadoras bolivianas entrevistadas optaron, por lo general, por el trabajo doméstico puertas adentro. De las diez entrevistadas, ocho trabajan bajo esta modalidad ${ }^{10}$. Esta es la

10 En la preferencia de la modalidad debe considerarse el momento migratorio, ya que, según un estudio llevado a cabo por Correa, Raynal y Musset (2013) en Santiago, las migrantes que llevan menos de dos años en el país optan por la modalidad puertas adentro, mientras que una vez que va pasando el tiempo, y sobre todo si traen a sus hijos, prefieren trabajar puertas afuera. 
opción preferida, pues así ellas pueden ahorrarse el pago de alojamiento. La totalidad de las entrevistadas envía remesas a sus familias, tanto aquellas que tienen hijos pequeños como las que tienen hijos adultos y que han formado ya su propia familia.

Nélida envía casi todo el dinero a su marido, pues casi no gasta acá. "Todito le mando, porque casi no gasto aquí, nada pues, la señora me da almuerzo, alojamiento, todito, pues" (Nélida, cuidadora boliviana de dos niños). Silvia envía también casi la totalidad del dinero percibido, pagando con ello el colegio particular de su hijo y el furgón que lo va a buscar. Daniela tiene cuatro hijos, tres de ellos en edad de ir al colegio. Pero como el dinero no le alcanzaba para comprar los útiles escolares, ni tampoco uniforme ni zapatos, tuvo que retirarlo del establecimiento. Manifiesta que acá se gana el doble.

Cuadro $\mathrm{N}^{\circ}$ 2: Modalidad de trabajo y remuneraciones de las trabajadoras domésticas bolivianas

\begin{tabular}{|l|l|l|}
\hline & Régimen puertas afuera o puertas adentro & Remuneración \\
\hline Lorena & Puertas adentro & 330.000 \\
\hline Cecilia & Puertas adentro & 280.000 \\
\hline Miriam & Puertas adentro & 250.000 \\
\hline Norma & Puertas afuera & 250.000 \\
\hline Lilian & Puertas afuera & 270.000 \\
\hline Soledad & Puertas adentro & 280.000 \\
\hline Delia & Puertas adentro & 280.000 \\
\hline Nélida & Puertas adentro & 300.000 \\
\hline Cintia & Puertas adentro & 250.000 \\
\hline Sara & Puertas adentro & 280.000 \\
\hline
\end{tabular}

Fuente: elaboración propia sobre la base de entrevistas realizadas.

\section{Sueldos}

La ley establece que las remuneraciones se fijarán de común acuerdo, no pudiendo incorporarse como remuneración el pago en especies, como alojamiento y alimentación ${ }^{11}$.

11 La disposición sobre las remuneraciones fue modificada hace dos años por la Ley 20.786, que entró en vigencia el 1 de enero de 2015. Anteriormente, la ley establecía un pago del 75\% del ingreso mínimo mensual, pues se atribuía el $25 \%$ restante a la entrega de alimentación y habitación. 
La remuneración de las trabajadoras domésticas chilenas es por lo general superior al ingreso mínimo, según los datos entregados por la Dirección del Trabajo (Celedón, 2015). Por otra parte, las entrevistas realizadas indican que los sueldos ofrecidos a las trabajadoras domésticas bolivianas no son inferiores a los percibidos por el servicio doméstico chileno.

Normalmente las migrantes entrevistadas reciben un pago mensual, aunque a dos de ellas se les cancela por día. El sueldo pagado por los servicios, como trabajo doméstico puertas adentro de las entrevistadas ${ }^{12}$, todos los cuales incluyen prestaciones de cuidado, oscila entre los $\$ 250.000$ y los $\$ 330.000$, promediando $\$ 281.250^{13}$, lo que está en consonancia con lo que se cancela por estos servicios en promedio en la región. Según datos de la Dirección del Trabajo, en Iquique el precio pagado por el servicio doméstico puertas adentro es de $\$ 250.096$ renta bruta, es decir, sobre este valor se debe considerar el descuento de las imposiciones (Celedón, 2015). Sobre el trabajo realizado puertas afuera, las dos cuidadoras bolivianas que trabajan en esta modalidad ganan en promedio $\$ 260.000$. El promedio indicado por la Dirección del Trabajo para el servicio doméstico puertas afuera en la región es de $\$ 239.040$, renta bruta ${ }^{14}$. Resulta interesante además puntualizar que los sueldos de las cuidadoras bolivianas entrevistadas están por sobre el salario mínimo, el que es de \$241.000 renta bruta, entre el 1 de julio de 2015 y el 1 de enero de 2016.

Al cotejar los sueldos percibidos por las cuidadoras bolivianas en Iquique con las remuneraciones de las trabajadoras domésticas en la región, se observa que es relativamente análogo. Esto quiere decir que la carencia de un contrato de trabajo no tiene incidencia sobre su sueldo, pues el dinero que ellas perciben sin contrato es similar al que reciben las trabajadoras domésticas con contrato.

Solo dos entrevistadas trabajan puertas afuera.

\$281.250 equivalen a US\$401, estimados al 27 de octubre de 2015.

4 Los datos fueron recogidos por la Dirección del Trabajo entre el 1 de enero y el 11 de mayo de 2015. Las entrevistas a migrantes bolivianas fueron realizadas entre septiembre y octubre de 2015. 


\section{Jornada laboral ${ }^{15,16}$}

El Código del Trabajo establece una diferencia en la jornada laboral según se trate de trabajadores puertas afuera o puertas adentro. Los trabajadores puertas afuera deben realizar una cantidad máxima de 45 horas semanales, aunque de común acuerdo y por escrito es posible establecer quince horas extras, las que se pagan adicionalmente ${ }^{17}$. La jornada diaria debe ser como máximo de doce horas, incluyendo un descanso mínimo de treinta minutos para colación. Los días domingos y festivos son libres.

Las trabajadoras domésticas puertas adentro tienen una normativa distinta, tanto en la jornada laboral semanal y diaria, como en el descanso semanal. El Código del Trabajo no fija una cantidad de horas diarias máxima en forma expresa, sin embargo, dispone en su artículo 149 inciso segundo:

Cuando vivan en la casa del empleador no estarán sujetos a horario, sino que éste será determinado por la naturaleza de su labor, debiendo tener normalmente un descanso absoluto mínimo de 12 horas diarias. Entre el término de la jornada diaria y el inicio de la siguiente, el descanso será ininterrumpido y, normalmente, de un mínimo de 9 horas. El exceso podrá fraccionarse durante la jornada y en él se entenderá incluido el lapso destinado a las comidas del trabajador (Código del Trabajo, 2015).

De la lectura del artículo se infiere que las trabajadoras domésticas puertas adentro trabajarán doce horas diarias como máximo. La ley tampoco expresa la cantidad máxima de horas semanales que deben realizar, sin embargo, estas también pueden inferirse de este artículo. Las trabajadoras pueden trabajar como máximo 72 horas semanales, ya que tienen derecho a descanso los días domingo. No obstante, la Ley 20.786, que modifica el Código del Trabajo y que entró en vigencia el 1 de enero de 2015, establece que desde el 21 de noviembre de 2015 el día sábado se considera como descanso semanal. Desde esa fecha, entonces, las trabajadoras domésticas puertas adentro — al igual que las puertas afuera - trabajan como máximo sesenta horas semanales.

15 Las migrantes bolivianas fueron entrevistadas en septiembre y octubre de 2015. La ley de las trabajadoras domésticas tiene una disposición sobre la jornada laboral que rige a partir del 21 de noviembre de 2015. Por lo tanto, el análisis realizado considera la legislación vigente al momento de realizar las entrevistas.

16 Este apartado ha sido realizado a partir de Leiva y Ross (2016).

17 La Ley 20.786, promulgada el 19 de octubre de 2014, estableció esa cantidad de horas semanales, así como la fijación de horas adicionales. 
Las jornadas laborales de las cuidadoras bolivianas entrevistadas excedían estos máximos. Las trabajadoras puertas afuera laboraban entre diez y diez horas y media al día, y las trabajadoras puertas adentro entre trece y quince horas diarias. Tanto a las trabajadoras puertas afuera como a las puertas adentro se les daba el domingo libre, aun cuando todas debían trabajar los días feriados. La mayor recarga de trabajo se observó en las trabajadoras puertas adentro, cuyas horas semanales trabajadas iba entre las 78 y las 90 horas.

\section{Previsión social}

Como las entrevistadas no tienen contrato de trabajo, tampoco pagan las imposiciones, por lo que en el futuro no tendrán derecho a recibir jubilación. Al consultarles por esta normativa, las entrevistadas afirman no tener interés en ello, puesto que no planean quedarse en Chile en forma definitiva. Los informantes claves entrevistados argumentan que esta es una situación problemática, pues cuando las migrantes bolivianas realizan imposiciones, al momento de irse del país pueden solicitar el retiro de su dinero. Sin embargo, es solamente un porcentaje del dinero lo que pueden retirar, perdiendo el resto. Ahora bien, en el caso de que se acojan al Convenio Multilateral Iberoamericano de Seguridad Social, pueden retirar el dinero que han ido depositando en sus cotizaciones previsionales. Sin embargo, lo que prima es el desconocimiento de este convenio y el insuficiente interés en preocuparse por su vejez. En efecto, si se tiene en cuenta su situación económica deteriorada, es comprensible que no piensen prevalentemente en su jubilación, sino en las necesidades inmediatas a ser cubiertas. En este contexto, les sería más útil no imponer una cantidad de dinero para su jubilación, sino que disponer de él de manera inmediata y solventar así las remesas para llevar a sus hogares en Bolivia.

\section{Salud}

Al no tener un contrato de trabajo, a las trabajadoras bolivianas no se les descuenta el pago de cotizaciones, lo que hace complejo, sino imposible, el acceso a las prestaciones de salud. Hasta hace poco tiempo, las prestaciones de salud en los servicios públicos otorgaban atención a los migrantes que estaban tramitando sus permisos de residencia, pero no a quienes se encontraban en una situación irregular. Desde junio de 2015, la 
circular A 15/6 sobre atención de salud de personas inmigrantes, dictada por el Ministerio de Salud, dispone la atención de salud a personas migrantes en casos calificados, con independencia de su situación migratoria y de la posesión de documentos oficiales. Se ordena que los establecimientos que integran el sistema público de salud deben entregar atención a mujeres durante el embarazo, parto y posparto, niños hasta los dieciocho años de edad, casos de urgencia médica, así como determinadas prestaciones, entre ellas métodos de regulación de fertilidad, vacunas, atención en caso de enfermedades transmisibles y educación sanitaria. La circular establece la presunción de carencia de recursos para todos los extranjeros que no cuenten con su documentación al día y que no estén tramitando su permiso de residencia. Aunque esta circular no es equivalente a los derechos de salud que tendrían las migrantes en caso de tener un contrato de trabajo, representa por lo menos un avance en relación con la situación anterior y ya no quedan - al menos en esos casos especiales - en la completa indefensión.

No obstante, existirían algunos funcionarios en los hospitales que presentan un fuerte rechazo a determinadas nacionalidades extranjeras (tales como población peruana, ecuatoriana, colombiana y boliviana) y conscientemente estarían negándoles el derecho a atención en salud en los casos que determina la circular.

\section{Malos tratos}

Las entrevistadas relatan que en ocasiones han sufrido maltrato en sus trabajos, aun cuando existen algunas excepciones que denotan una muy buena relación con sus empleadoras. Para graficar esto, presentamos los casos de Cintia y Lilian. La primera ha recibido un evidente maltrato por parte de sus empleadores, en tanto que la segunda expresa que el buen trato ha sido la tónica, aun cuando esta situación cambiara radicalmente meses más tarde.

Cintia se siente muy mal en su lugar de trabajo. Cuenta que le dan de comer luego de que todos los miembros de la familia han comido; es más, manifiesta que le dan las sobras, a veces incluso le dan comida de uno o dos días anteriores. Relata que para el terremoto (el 16 de septiembre de 2015 se dio alerta de tsunami en casi todo el territorio nacional), sus empleadores tenían todo listo para evacuar, su furgón se encontraba lleno con sus pertenencias principales y estaban todos arreglados para partir, pero a ella no le dijeron nada. "Me iban a dejar aquí sola" (Cintia, cuidadora boliviana de tres niños). Ella tenía 
mucho miedo, pero nadie le decía nada. La vivienda donde trabaja está emplazada en una zona segura en Iquique, pero nadie se lo explicó.

Como contraste, Lilian, que para el momento de la entrevista tiene ocho meses de embarazo, declara recibir un excelente trato por parte de su empleadora, quien incluso en el último mes por propia iniciativa le da más horas de descanso. Afirma que le dan un trato muy familiar y que ella se siente muy a gusto con su empleadora. Sin embargo, esa situación cambió completamente. A Lilian la encontramos casualmente en la Congregación del Buen Pastor dos meses después de haberla entrevistado, cuando su bebé ya tenía un mes, pero por entonces la situación había cambiado: la empleadora le había bajado el sueldo por debajo del mínimo, pasando de $\$ 270.000$ a $\$ 200.000$, bajo el argumento de que Lilian llevaba a su bebé a su trabajo, que necesitaba más agua para bañarlo y para prepararle su mamadera, y que por esos gastos que estaba realizando, debía bajarle el sueldo. Además, había un hostigamiento constante hacia ella, pues ahora le exigía muchas más actividades que antes. Esto nos hace pensar que, si bien podemos encontrar excepciones y empleadoras que pueden brindar un muy buen trato, este puede no ser sustentable en el largo plazo y revertirse completamente.

\section{Conclusiones}

Este artículo se centró en las condiciones laborales de las trabajadoras domésticas migrantes bolivianas en Iquique, que forman parte de una cadena global de cuidado. La investigación se acotó a las trabajadoras domésticas que constantemente salían e ingresaban al territorio. Las diez entrevistadas se desempeñaban sin un contrato de trabajo, lo que probablemente es resultado de varios factores: la cercanía geográfica entre Iquique y Bolivia, los marcos legales que regulan la migración entre ambos países, los elevados costos de un permiso de trabajo, entre otros. Las migrantes bolivianas realizan viajes con un ritmo de noventa días a su país porque han ingresado con visa de turismo. Además de ello, tres migrantes declaran viajar con esa periodicidad por el deseo de ver a sus hijos cada tres meses. Uno de los factores que ciertamente influye en estos viajes está dado por el elevado costo del permiso de residencia, prefiriendo guardar ese dinero para enviarlo a sus familias. Otro de los factores que determina este ritmo de viaje es la cercanía geográfica de Iquique respecto de Bolivia. En tanto zona fronteriza, se favorece un constante movimiento poblacional circulatorio (Cortés, 2009; Tarrius, 2000; Tapia y González, 2014; Tapia y Parella, 2015; Tapia y Chacón, 2016; Leiva y Ross, 2016; Comelin y Leiva, 2017). 
Este trabajo ha aportado al conocimiento del trabajo de cuidado remunerado realizado en una zona fronteriza. De los hallazgos se colige que deben ser utilizadas ciertas categorías explicativas que no habían sido consideradas en el trabajo de cuidado, como la circulación migratoria (Cortés, 2009) de las extranjeras que otorgan este servicio como empleadas domésticas. La labor de cuidado realizada por un cierto grupo de trabajadoras domésticas bolivianas en la zona fronteriza de Tarapacá constituye una práctica de circulación que hasta ahora ha sido poco estudiada, destacando el trabajo de Leiva y Ross (2016) y el de Comelin y Leiva (2017), que analizan la migración circular de cuidadoras bolivianas en Iquique. A la literatura que vincula el trabajo de cuidado con la migración, deben agregarse por tanto los resultados encontrados en una zona fronteriza: se trata de un cuidado remunerado con características específicas, siendo una de estas la carencia de un contrato de trabajo, aun cuando las migrantes se encuentren en una condición migratoria regular. Esta situación las expone a condiciones precarias de empleo, extensas jornadas laborales y malos tratos.

En la medida en que se implementen soluciones legales para que las cuidadoras bolivianas fronterizas tengan la posibilidad de salir del país y visitar regularmente a sus hijos, se evitará que se empleen sin un contrato de trabajo y con ello se reducirán las posibilidades de tener que estar en condiciones precarias de empleo. Estudios recientes han abordado las condiciones laborales altamente precarias de trabajadores fronterizos en el extremo norte de Chile, refiriéndose al trabajo realizado por migrantes peruanos en Arica, fundamentalmente en la agricultura (Stefoni, Leiva y Marticorena, 2017; Tapia, Liberona y Contreras, 2017).

Sería necesario, por tanto, que la legislación nacional considerara de manera expresa la condición fronteriza de los migrantes y los habilitara a trabajar. Esta situación podría presentarse de manera favorable, ya que el anteproyecto de la Ley de Migraciones, que debería ingresar prontamente al Congreso y al cual los autores de este artículo han tenido acceso, menciona la categoría de trabajador fronterizo, aun cuando se explica de manera insuficiente cuáles serán sus disposiciones (Ministerio del Interior y de Seguridad Pública, 2016). Sin duda esta podría ser una oportunidad para legislar sobre los trabajadores fronterizos y disminuir en este caso las condiciones deplorables de las cuidadoras bolivianas fronterizas.

En segundo lugar, podría aprovecharse la legislación de las trabajadoras domésticas, la que contempla una interesante norma para las trabajadoras domésticas puertas adentro, que comenzó a regir el 21 de noviembre de 2015. Según dicho reglamento, las trabajadoras domésticas tienen libres, además de los días domingos, los sábados y los 
festivos. Los domingos son irrenunciables, pero los sábados se pueden pactar y cambiar por otro día, siempre que se haga uso del descanso dentro del mes. Los festivos son igualmente pactables, pero se pueden hacer efectivos en un rango de noventa días. Estas modificaciones a la ley favorecen a las migrantes fronterizas, puesto que ellas podrían solicitar permisos de a lo menos cinco días en un mes, en la medida que intercambien tres días sábados por otros días de la semana, y lo adhieran a un sábado y domingo libre. Tendrían entonces cinco días libres seguidos, si así lo acuerdan las partes, y en ese tiempo podrían viajar a visitar a sus familias. Esta modalidad no implicaría cambios en el procedimiento actualmente existente, pues las migrantes bolivianas continuarían solicitando una visa temporaria con motivos laborales, acogiéndose además al permiso de residencia por un año a través del convenio MERCOSUR. La diferencia es que las migrantes bolivianas que realizan una circulación migratoria podrían tener un contrato de trabajo.

Por último, podría pensarse en que el Estado contemple las necesidades de mano de obra del país y la constatación de que ciertos nichos laborales están siendo cubiertos por migrantes. Para facilitar el desempeño de mano de obra extranjera podrían implementarse políticas públicas eficaces e innovadoras, como la que existe en Italia para cubrir las necesidades de cuidado de la población, y que ha liberado a las migrantes rumanas de solicitar un permiso de trabajo para desempeñar esta labor (Ottonelli y Torresi, 2016). En la medida en que se realice una acción coordinada entre los organismos del Estado para cubrir la creciente demanda que existe de trabajo de cuidado en el país, ejemplos como este pueden contribuir a satisfacer esta necesidad y con ello aminorar las posibilidades de que las cuidadoras migrantes fronterizas realicen su trabajo en condiciones de extrema precariedad.

\section{Referencias}

Acosta, E. (2013). Entre la necesidad y el no reconocimiento: la valoración de la dimensión temporal en las estrategias familiares para la contratación de cuidadoras domésticas inmigrantes en España y Chile. Si Somos Americanos. Revista de Estudios Transfronterizos 13(2), 141-164.

Acosta, E. (2015). Cuidados en crisis. Mujeres migrantes hacia España y Chile. Deusto: Deusto Publicaciones. 
Ariza, M. (2012). Vida familiar transnacional en inmigrantes de México y República Dominicana en dos contextos de recepción. Si Somos Americanos. Revista de Estudios Transfronterizos 12(1), 17-47.

Arriagada, I. y Moreno, M. (2011). La constitución de cadenas globales de cuidado y las condiciones laborales de las trabajadoras peruanas en Chile. En C. Stefoni (ed.), Mujeres inmigrantes en Chile: ¿Mano de obra o trabajadora con derechos? (pp. 151-191). Santiago de Chile: Ediciones Universidad Alberto Hurtado.

Arriagada, I. y Todaro, R. (2012). Cadenas globales de cuidado. El papel de las migrantes peruanas en la provisión de cuidados en Chile. Santo Domingo: INSTRAW-ONU Mujeres.

Baby-Collin, V. y Cortes, G. (2014). Nuevos despliegues del campo migratorio boliviano frente a la crisis. Revista CIDOB d'Afers Internacionals 106-107, 61-83.

Baldassar, L. y Merla, L. (eds.). (2014). Transnational Families, Migration and the Circulation of Care: Understanding Mobility and Absence in Family Life. Nueva York y Abingdon: Routledge.

Batthyáni, K. (2004). Cuidado infantil y trabajo. ¿Un desafío exclusivamente femenino? Montevideo: CINTERFOR.

Bettio, F., Simonazzi, A. y Villa, P. (2006). Change in Care Regimes and Female Migration: the "Care Drain" in the Mediterranean. Journal of European Social Policy 16(3), 271-285.

Carrasco, C., Borderías, C. y Torns, T. (eds.). (2011). El trabajo de cuidados: Historia, teoría y políticas. Madrid: Los libros de la Catarata.

Celedón, S. (2015). Asesoras de hogar ganan en promedio \$270 mil en Chile, mientras en la Región Metropolitana el sueldo llega a \$300 mil. El Mercurio, 17 de mayo, pp. B4, B5.

Código del Trabajo (2015). Dirección del Trabajo, Santiago de Chile.

Comelin, A. y Leiva, S. (2017). Cadenas globales de cuidado entre Chile y Bolivia y migración circular. En J. Berríos e I. Bortolotto (eds.), Interculturalidad y movilidad humana. Santiago de Chile: Fundación Scalabrini/INCAMI. En prensa. 
Correa, V. y Vidal, D. (2013). Geografía de la crisis del cuidado en Santiago: una aproximación centrada en la demanda de mano de obra extranjera. En V. Correa, I. Bortolotto y A. Musset (eds.), Geografías de la espera. Migrar, habitar y trabajar en la ciudad de Santiago, Chile. 1990-2012 (pp. 285-310). Santiago de Chile: Uqbar Editores.

Correa, V., Raynal, J. y Musset, A. (2013). Una dimensión espacio-temporal de la espera: El patrón residencial de las inmigrantes latinoamericanas en la última década en Santiago de Chile. En V. Correa, I. Bortolotto y A. Musset (eds.), Geografías de la espera. Migrar, habitar y trabajar en la ciudad de Santiago, Chile. 1990-2012 (pp. 311-349). Santiago de Chile: Uqbar Editores.

Cortés, G. (2009). Migraciones, construcciones transnacionales y prácticas de circulación. Un enfoque desde el territorio. Párrafos geográficos 8(1), 35-53.

Departamento de Extranjería y Migración (2010). Informe Anual. Departamento de Extranjería y Migración. Ministerio del Interior. Recuperado de: http://www. extranjeria.gob.cl/filesapp/Informe\%20Estimacion\%20Poblacion\%20Extranjeros\%20 2008.pdf.

---- (2016). Migración en Chile 2005-2014. Departamento de Extranjería y Migración, Santiago de Chile.

Dirección del Trabajo (2014). Dictamen 4268/068 Fija sentido y alcance Ley No 20.786, de 27.10.2014, que modifica la jornada, descanso y composición de la remuneración de los trabajadores y trabajadoras de casa particular, y prohíbe la exigencia de uniforme en lugares públicos.

Fernández, J.A. y Tobío, C. (2007). Andalucía: dependencia y solidaridad en las redes familiares. Sevilla: Instituto de Estadística de Andalucía.

Glaser, B. y Strauss, A. (1967). The Discovery of Grounded Theory: Strategies for Qualitative Research. Nueva York: Aldine Publishing Company.

Gonzálvez, H. y Acosta, E. (2015). Cruzar las fronteras desde los cuidados: La migración transnacional más allá de las dicotomías analíticas. En M. Guizardi (ed.), Las fronteras del transnacionalismo. Límites y desbordes de la experiencia migrante en el centro y norte de Chile (pp. 126-149). Santiago de Chile: UTA y Ocho Libros.

Grimson, A. y Guizardi, M. (2015). Matices y límites del transnacionalismo: los contextos de la migración en Chile. En M. Guizardi (ed.), Las fronteras del transnacionalismo. 
Limites y desbordes de la experiencia migrante en el centro y norte de Chile (pp. 13-34). Santiago de Chile: UTA y Ocho Libros.

Hinojosa, A. (2009). Buscando la vida. Familias bolivianas transnacionales en España. La Paz: CLACSO y Programa de Investigación Estratégica en Bolivia.

Hinojosa, A., Pérez, L. y Cortez, G. (2000). Idas y venidas. Campesinos tarijeños en el norte Argentino. La Paz: Programa de Investigación Estratégica en Bolivia.

Hochschild, A.R. (2001). Las cadenas globales de afecto y asistencia y la plusvalía emocional. En A. Giddens y W. Hutton (eds.), El límite: la vida en el capitalismo global (pp. 187209). Barcelona: Tusquets.

Hondagneu-Sotelo, P. y Avila, E. (1997). “I'm here, but I'm there”: The Meanings of Latina Transnational Motherhood. Gender \& Society 11(5), 548-571.

Leiva, S. (2015). Organización social del cuidado en Bolivia y Chile: Estado y cuidadanía. Revista Austral de Ciencias Sociales 28, 61-81.

Leiva, S. y Comelin, A. (2015). Conciliación entre la vida familiar y laboral: evaluación del programa IGUALA en una empresa minera en la región de Tarapacá. POLIS Revista Latinoamericana 42, 345- 368. Recuperado de: https://polis.revues.org/11385.

Leiva, S. y Ross, C. (2016). Migración circular y trabajo de cuidado: Fragmentación de trayectorias laborales de migrantes bolivianas en Tarapacá. Psicoperspectivas: Individuo y Sociedad 15(3), 56-66.

Lewis, J. (1998). Gender, Social Care, and Welfare State Restructuring in Europe. Aldershot: Ashgate.

Ministerio del Trabajo y Previsión Social. Ley 20.786 modifica la jornada, descanso y composición de la remuneración de los trabajadores de casa particular, y prohíbe la exigencia de uniforme en lugares públicos, del 27.10.2014. Ministerio del Trabajo y Previsión Social, Estado de Chile.

Ministerio de Salud (2006). Circular A 15/06 Atención de salud de personas inmigrantes. Ministerio de Salud, Estado de Chile. 
Martínez, J. (2003). El encanto de los datos. Sociodemografía de la inmigración en Chile según el censo de 2002. Santiago de Chile: CEPAL.

Martínez, J. y Soffia, M. (2013). Una aproximación descriptiva y sociodemográfica de las mujeres inmigrantes en Santiago de Chile, desde el registro de CIAMI. En V. Correa, I. Bortolotto y A. Musset (eds.), Geografías de la espera. Migrar, habitar y trabajar en la ciudad de Santiago, Chile. 1990-2012 (pp. 63-95). Santiago de Chile: Uqbar Editores.

Ministerio de Desarrollo Social (2015). CASEN 2013. Trabajo. Síntesis de resultados. Ministerio de Desarrollo Social, Santiago de Chile. Recuperado de: http://observatorio. ministeriodesarrollosocial.gob.cl/documentos/Casen2013_Trabajo.pdf.

Ministerio del Interior y de Seguridad Pública (2016). Anteproyecto de migración. Inédito.

Ottonelli, V. y Torresi, T. (2016). Temporary Migration and the Shortcomings of Citizenship. The Case of Female Circular Migration from Romania to Italy. En C. Solé, S. Parella, T. Sordé Martí y S. Nita (eds.), Impact of Circular Migration on Human, Political and Civil Rights. A Global Perspective (pp. 153-172). Brujas: United Nations University (UNU).

Parella, S. (2003). Mujer, inmigrante y trabajadora. La triple discriminación. Barcelona: Editorial Anthropos.

Pérez Orozco, A. (2007). Cadenas globales de cuidado. Serie Género, Migración y Desarrollo. Documento de trabajo No 2. Santo Domingo: INSTRAW-ONU Mujeres.

Pérez Orozco, A. y López Gil, S. (2011). Desigualdades a flor de piel: Cadenas globales de cuidados. Concreciones en el empleo de hogar y articulaciones políticas. Navarra: INSTRAW-ONU Mujeres.

Ramos, R. y Urbina, D. (2012). Percepción de las mujeres inmigrantes usuarias de la pastoral de migraciones Incami-Iquique en cuanto a su vinculación con las redes de apoyo en la región de Tarapacá durante el segundo semestre del año 2011. Tesis no publicada para optar al título de Trabajadora Social, Universidad Arturo Prat, Iquique, Chile.

Rivas, A.M. y Gonzálvez, H. (2009). Familias transnacionales colombianas. Transformaciones y permanencias en las relaciones familiares y de género. Madrid: Catarata.

Salazar Parreñas, R. (2001). Servants of Globalization. Women, Migration and Domestic Work. California: Stanford University Press. 
Salazar, C., Jiménez, E. y Wanderley, F. (2010). Migración, cuidado y sostenibilidad de la vida. La Paz: CIDES-UMSA, INSTRAW Naciones Unidas, Plural Editores.

Salvo, I. y Gonzálvez, H. (2015). Monoparentalidades electivas en Chile: emergencias, tensiones y perspectivas. Psicoperspectivas, 14(2), 40-50.

Stefoni, C. (2009). Migración, género y servicio doméstico. En M.E. Valenzuela y C. Mora (eds.), Trabajo doméstico. Un largo camino hacia el trabajo decente (pp. 191-232). Santiago de Chile: OIT.

Stefoni, C., Leiva, S. y Marticorena, T. (2017). Migración circular y trabajo agrícola por día en los valles del norte de Chile. La relación capital trabajo en los márgenes del desarrollo. Inédito.

Tapia, M. (2015). Frontera, movilidad y circulación reciente de peruanos y bolivianos en el norte de Chile. Estudios Atacameños 50, 195-213.

Tapia, M. y Chacón, F. (2016). Vínculos transfronterizos: vida, movilidad y comercio en el Barrio Boliviano de Iquique, Chile. REMHU, Revista Interdisciplinar de la Movilidad Humana 47, 131-152.

Tapia, M. y González, A. (2014). Fronteras, regiones fronterizas y migraciones. Entre apertura, integración y cierre. En M. Tapia y A. González (eds.), Regiones transfronterizas. Migración y los desafíos para los Estados nacionales latinoamericanos (pp. 17-39). Santiago de Chile: RIL editores y Universidad Arturo Prat.

Tapia, M. y Parella, S. (2015). Las regiones fronterizas para el estudio de la migración y la circulación. Un análisis a partir de dos casos ilustrativos. En M. Guizardi (ed.), Las fronteras del transnacionalismo. Límites y desbordes de la experiencia migrante en el centro y norte de Chile (pp. 173-206). Santiago de Chile: UTA y Ocho Libros.

Tapia, M., Liberona, N. y Contreras, Y. (2017). El surgimiento de un territorio circulatorio en la frontera chileno-peruana: estudio de las prácticas socio-espaciales fronterizas. Revista de Geografía Norte Grande. En prensa.

Tarrius, A. (2000). Leer, describir, interpretar. Las circulaciones migratorias: conveniencia de la noción de "territorio circulatorio". Los nuevos hábitos de la identidad. Relaciones (21)83, 39-66. 
Thomas, C. (1993). De-constructing Concepts of Care. Sociology (27)4, 649-669.

Wanderley, F. (2009). Crecimiento, empleo y bienestar social. ¿Por qué Bolivia es tan desigual? La Paz: CIDES-UMSA, Plural Editores.

Williams, F. (2012). Converging Variations in Migrant Care Work in Europe. Journal of European Social Policy (22)4, 363-376.

Yeates, N. (2012). Global Care Chains: a State-of-the-art Review and Future Directions in Care Transnationalization Research. Global Networks (12)2, 135-154. 